\title{
ACERCA DE LA IMPUTACIÓN DE RESPONSABILIDAD CIVIL POR ILÍCITOS ANTICOMPETITIVOS ENTRE RIVALES EN CHILE
}

\section{A CRITERION FOR ATTRIBUTING TORT LIABILITY DERIVED FROM ANTICOMPETITIVE WRONGS BETWEEN RIVALS IN CHILE}

\author{
Cristián Banfi del Río*
}

\begin{abstract}
RESUMEN: En trabajos previos hemos argumentado que es imperativo aplicar la responsabilidad extracontractual por daños provenientes de los actos de competencia desleal -ex artículos 2314 y siguientes del Código Civil en relación a la Ley 20.169, de 2007- en congruencia con la libertad de competir. En este sentido, hemos sostenido que la responsabilidad civil en esta área presupone el dolo o, al menos, la culpa grave del autor del daño, factores indiciarios de comportamientos que exceden la libertad de competir e implican un abuso del derecho a dañar que esta abarca ${ }^{1}$. En el presente artículo extendemos este análisis a la responsabilidad civil derivada de atentados a la libre competencia entre rivales en Chile ${ }^{2}$.
\end{abstract}

Palabras clave: Responsabilidad civil, conducta anticompetitiva, dolo.

ABSTRACT: In previous works we have argued for the need to apply tort liability for damages arising from unfair competitive acts -pursuant to articles 2314 and following of the Civil Code in relation to Law 20169, of 2007- congruently with the freedom to compete. In this sense, we have maintained that tort liability in this area presupposes intention or, at least, gross negligence on the part of the wrongdoer, as those factors indicate a behavior in excess of the liberty to compete and imply the abuse of the right to harm encompassed by such freedom. In this article we extend that analysis to tort liability ensuing from antitrust conduct among competitors in Chile.

Key words: Tort liability, anticompetitive conduct, intention.

\section{INTRODUCCIÓN}

1. En Chile, las personas gozan de libertad para emprender cualquier actividad económica siempre que no infrinjan las normas legales pertinentes, la seguridad nacional, la

\footnotetext{
* Licenciado en Derecho, Pontificia Universidad Católica de Chile, Magíster en Derecho Privado, Universidad de Chile, Magíster y Doctor en Derecho, Universidad de Cambridge; Profesor Asociado de Derecho Civil, Universidad de Chile. Este artículo forma parte del Proyecto Fondecyt de iniciación No 11121336 ("Revisión crítica de la responsabilidad civil por daños entre competidores por conductas anticompetitivas en Chile") y del Proyecto Anillo de Investigación Asociativa, código SOC 1111 de Conicyt. Dirección postal: Pío Nono 1, Providencia. Correo electrónico: cbanfi@asyc.com.

${ }^{1}$ BANFI (2012a) pp. 685-704; BANFI (2012b) pp. 165-192; BANFI (2011b) pp. 313-361; BANFI (2007a) pp. 431-448; Banfi (2007b) pp. 9-57.

2 Un examen crítico del tópico referido al derecho anglosajón, véase en BANFI (2011a) pp. 83-112.
} 
moral y el orden público ${ }^{3}$. Junto al derecho de propiedad la libertad económica conforma el orden público económico consagrado en la Carta Fundamental ${ }^{4}$.

La libertad económica abarca las libertades de trabajo, de empresa y de competencia, comprendiendo esta última las libertades para acceder, permanecer y salir del mercado. Los competidores están facultados para luchar por la clientela salvo que perpetren actos desleales o anticompetitivos 5 . Asimismo, los ilícitos anticompetitivos son perseguidos, declarados y sancionados en un proceso independiente -iniciado comúnmente a instancias de la Fiscalía Nacional Económica (FNE) - por el Tribunal de Defensa de la Libre Competencia (TDLC) y por la Corte Suprema, esta última conociendo del recurso de reclamación interpuesto contra la sentencia pronunciada por aquel tribunal especial.

2. La libertad para competir no debe ser abusiva ni contravenir las regulaciones económicas (y estas no pueden afectar dicha garantía constitucional en su esencia ni someterla a condiciones que impidan su libre ejercicio) ${ }^{6}$, las normas morales (incluida la buena fe y las buenas costumbres comerciales) y el orden público ${ }^{7}$. La moral y el orden público impregnan el derecho civil y, a medida que la sociedad evoluciona, limitan la autonomía privada $^{8}$. La moral y las buenas costumbres son criterios que favorecen un mercado de contratos libremente negociados y de bienes libremente transferidos, pero ellos operan $a$ posteriori, por ejemplo, invalidando los contratos que adolecen de objeto o causa ilícita? Por eso se ha representado la necesidad de implementar una regulación especial, de derecho público, que salvaguarde ex ante la competencia contra los abusos de poder económico e imponga obligaciones positivas y sanciones cuasi penales a los contraventores ${ }^{10}$.

3. Lo señalado en el párrafo anterior implica que mientras el derecho administrativo juega un papel principal en la defensa de la competencia, al derecho privado toca cumplir una misión más bien marginal. En efecto, las normas que protegen la libre competencia integran el derecho público, cuyo objeto de preocupación primordial son los consumidores y el mercado, no los adversarios individualmente considerados.

En este sentido, el derecho de la competencia es una disciplina política, pues la autoridad pública encargada de su cumplimiento -siguiendo el criterio de minimis ${ }^{11}$ y usando los siempre limitados recursos fiscales- selecciona y sanciona los ilícitos de mayor connotación social, que representan una grave amenaza para los consumidores y el mercado.

\footnotetext{
3 Art. $19 \mathrm{~N}^{\circ} 21 \mathrm{CPR}$.

4 Guzmán (2001) p. 27 y ss.; Fermandois (2006) p. 73; Peñailillo (2006) p. 87.

5 Font (1987) pp. 180-181; Ruiz-Tagle (2000).

6 Art. $19 \mathrm{~N}^{\circ} 26 \mathrm{CPR}$.

7 Evans (1986) p. 318; GuZMán (2001) p. 255; Barandiarán (2002) p. 497 y ss.; ValdÉs (2006) pp. 127 y 231-232; Fermandois (2006) p. 124 y ss.

8 LIRA (1944) pp. 260 y 322.

9 Arts. 10, 1461, 1467 y 1682 CC.

10 Nehme y Werner (2008) passim.

11 Esto es, descartando la persecución de conductas cuyo impacto anticompetitivo es intrascendente: Völk v. Vervaecke (1969).
} 
Como no es posible perseguir todo hecho, acto, contrato o acuerdo que impida, restrinja o falsee la libre competencia, o que tenga la potencialidad de acarrear una o más de estas secuelas, el esfuerzo persecutor se concentra en las prácticas más dañinas para el interés público, en particular los cárteles -vale decir, acuerdos o prácticas concertadas entre empresas que tienen, entre otras finalidades, fijar precios de compra o venta, limitar la producción o repartirse cuotas o zonas de mercado- y el abuso de posición dominante en el mercado relevante.

4. A su turno, la responsabilidad civil despliega una misión ex post y esencialmente resarcitoria del perjuicio individual derivado de los atentados a la libre competencia ${ }^{12}$. Desde esta perspectiva, la responsabilidad civil solo puede contribuir indirectamente a prevenir la comisión de conductas anticompetitivas perniciosas para la economía y los consumidores. De hecho, sin la detección y declaración de un ilícito anticompetitivo por la autoridad pública es virtualmente imposible llevar adelante un juicio indemnizatorio con razonables posibilidades de triunfo.

En efecto, cabe recordar que la sentencia firme pronunciada por el TDLC y/o la Corte Suprema produce cosa juzgada material en el litigio civil incoado a continuación, pues como dispone el artículo 30 inciso $2^{\circ}$ del DL 211 "El tribunal civil competente, al resolver sobre la indemnización de perjuicios, fundará su fallo en las conductas, hechos y calificación jurídica de los mismos, establecidos en la sentencia del Tribunal de Defensa de la Libre Competencia, dictada con motivo de la aplicación de la presente ley"13.

De esta manera, la acción de reparación del daño sufrido por un competidor individual es un instrumento complementario de la persecución pública de las infracciones a la libre competencia. El éxito del private enforcement depende en buena medida de la efectividad del public enforcement, lo que se asemeja a la situación que presentan los estados miembros de la Unión Europea y, por el contrario, contrasta fundamentalmente con el sistema norteamericano en donde el peso de la aplicación de las reglas de la libre competencia descansa en los privados. Con todo, la sola existencia de una regla como el citado artículo 30, que permite demandar la responsabilidad civil del autor del ilícito anticompetitivo, puede promover la observancia de las reglas del juego.

\section{NECESIDAD DE DOLO O CULPA LATA}

1. Las conductas anticompetitivas dan lugar a una responsabilidad infraccional que debe ser aplicada con estricto apego a los principios constitucionales de legalidad y culpabilidad $^{14}$. El acto anticompetitivo y las sanciones aparejadas al mismo son cualitativamente

12 Baylos (1978) p. 359; De la Vega (2001) p. 56.

13 Énfasis agregado. El inciso $1^{\circ}$ del referido precepto estatuye lo siguiente: "La acción de indemnización de perjuicios a que haya lugar, con motivo de la dictación por el Tribunal de Defensa de la Libre Competencia de una sentencia definitiva ejecutoriada, se interpondrá ante el tribunal civil competente de conformidad a las reglas generales, y se tramitará de acuerdo al procedimiento sumario, establecido en el Libro III del Título XI del Código de Procedimiento Civil'.

14 Art. $19 \mathrm{~N}^{\circ} 3 \mathrm{CPR}$. 
equivalentes a los ilícitos penales. El hecho que la responsabilidad por atentados a la libre competencia no sea denominada "responsabilidad penal" obedece a una decisión política antes que jurídica ${ }^{15}$. Por eso, no cabe presumir la responsabilidad infraccional, es necesario observar el principio non bis in idem y el castigo tiene que ser proporcionado al ilícito ${ }^{16}$.

Si bien alguna vez se ha sugerido que los actos anticompetitivos darían lugar a una responsabilidad estricta, ya que el artículo $3^{\circ}$ del DL 211 los define con referencia a su objeto o efecto en el mercado haciendo abstracción de los motivos del autor ${ }^{17}$, no es posible prescindir de los criterios que informan la responsabilidad penal al momento de imputar responsabilidad por ilícitos anticompetitivos. Esta clase de responsabilidad presupone un factor de imputación subjetivo que es el dolo. Además, como se ha advertido en España, la responsabilidad estricta es inapropiada para regular actividades no riesgosas entre las cuales se incluye la competencia ${ }^{18}$.

De hecho, la Corte Suprema ha declarado que la intención de restringir o entorpecer la libre competencia es consustancial al ilícito anticompetitivo ${ }^{19}$. Por ejemplo, en un cártel dos o más personas se conciertan con la intención positiva de producir efectos perjudiciales para el mercado. Con todo, la prueba del dolo es compleja. Así, el cobro sincronizado o coincidente de precios similares no acredita de manera concluyente la existencia de colusión si los demandados prueban otras causas posibles, tales como la equivalencia de los servicios que prestan o una competencia severa que fuerce a imitar rápidamente los métodos comerciales de los rivales $^{20}$.

2. El daño causado accidental o negligentemente a los contrincantes está justificado en cuanto efecto colateral, secundario e inevitable del ejercicio de la libertad de competir, la que beneficia a los consumidores. La competencia legítima suele ser agresiva ${ }^{21}$. De ahí que la jurisprudencia chilena asevere que las empresas deben sobreponerse a sus competidores mediante estrategias comerciales e instrumentos de mercado ${ }^{22}$.

Por ende, la responsabilidad civil solo puede ser imputada tras una evaluación de los intereses en conflicto de víctima y dañador. El elemento decisivo es si el daño proviene de un acto de competencia legítima o, por el contrario, del abuso de la libertad de competir ${ }^{23}$. El abuso del derecho está representado por la propia conducta anticompetitiva ${ }^{24}$. A diferencia de otros ámbitos de la responsabilidad civil, los contendores no están vinculados por un

\footnotetext{
15 Tiedemann (1993) pp. 62, 85 y ss.; JaKobs (1996) p. 15 y ss.; Roxin (1997) pp. 72-73.

16 "Que, los principios inspiradores del orden penal contemplados en la Constitución Política de la República han de aplicarse, por regla general, al derecho administrativo sancionador, puesto que ambos son manifestaciones del ius puniendi propio del Estado": Sentencia TC N² 44 (1996), cons. 9; Cury (2005) p. 303; Valdés (2006) passim.

17 Vergara (2006) passim.

18 PeÑa (2000) p. 235 y ss.

19 Voissnet S.A. con Compañia de Telecomunicaciones de Chile S.A. (2007).

20 Fiscal Nacional Económico con Copec y Otras (2005); Fiscal Nacional Económico con Ultramar y Otros (2006).

21 Tunc (1974) p. 93 y ss.

22 Intergas con Dirección de Vialidad de la Décima Región de los Lagos (2004), en particular cons. $9^{\circ}$ a $11^{\circ}$.

23 Peña (2000) p. 229 y ss.; Markesinis y Unberath (2002) p. 889 y ss.; Van Dam (2006) p. 70.

24 Barros (2006) p. 1044 y ss.
} 
deber de cuidado general ni particular. Es decir, el régimen indemnizatorio aplicable a los competidores no está ni puede quedar supeditado a la culpa ordinaria y menos podría desencadenar una responsabilidad estricta. Y si bien los rivales acostumbran dañarse incluso en forma deliberada, el dolo limita efectivamente el principio neminem laedere. Esto es, el dolo tiñe de ilicitud lo que de otro modo sería un comportamiento comercial legítimo, convirtiéndolo en un acto desleal o anticompetitivo.

Por consiguiente, la responsabilidad civil entre competidores proviene de conductas ejecutadas con la intención de dañar, como un fin o como un medio para otro fin. Pero también es posible imputar esta clase de responsabilidad cuando el autor del hecho se ha conducido con extrema imprudencia, toda vez que en virtud del artículo 44 del Código de Bello, la culpa lata es asimilada al dolo para todos los efectos en el derecho privado, incluyendo la responsabilidad contractual y extracontractual. Es más, la negligencia grosera es la categoría del derecho civil que equivale al dolo eventual propio del derecho penal e implica conducirse con total desconsideración hacia los intereses ajenos ${ }^{25}$.

3. Ahora bien, en atención a lo dispuesto en el artículo 30 del DL 211, constada la existencia de un acuerdo colusorio, de un abuso de posición dominante o de otro atentado a la libre competencia, la discusión en el litigio indemnizatorio subsiguiente se centrará en el daño y la relación causal. Por tanto, el actor deberá acreditar que el ilícito anticompetitivo le infligió directamente un perjuicio específico diverso del impacto nocivo que esa conducta irrogó al mercado y a los consumidores. Lo anterior, por cuanto el dolo ínsito en el ilícito anticompetitivo consiste en la intención de causar detrimento al mercado y a los consumidores, y no a uno o más individuos ${ }^{26}$. Sin embargo, como la sentencia del TDLC y/o de la Corte Suprema que constata ese atentado vincula al juez que conoce de la acción civil, en este proceso posterior no será necesario probar el hecho ilícito ni el dolo.

En España se afirma que la conducta anticompetitiva declarada por la autoridad respectiva debe ser tratada como prueba irrefutable de la culpa del demandado, dada la proximidad entre la ilicitud y la culpabilidad. Por ende, la responsabilidad extracontractual es interpretada y aplicada como un estatuto de responsabilidad estricta calificada por el resultado ${ }^{27}$. Igualmente, en Francia la declaración de conducta anticompetitiva es prueba irrefragable y produce cosa juzgada material en el juicio de responsabilidad civil ulterior ${ }^{28}$. Análogamente, los juristas y tribunales chilenos presumen la culpa del demandado de la conducta anticompetitiva, ya que el artículo 30 del DL 211 no exige probar la culpa sino que los hechos y la calificación jurídica de los mismos establecida por el TDLC y/o la Corte son datos inamovibles en el juicio resarcitorio. Se trataría de culpa contra legalidad ${ }^{29}$.

25 Sobre el particular, véase BANFI (2003), BANFI (2000) y BANFI (2012c) passim.

26 VAldés (2006) passim; BANFi (2007a) pp. 445-446.

27 De la Vega (2001) p. 200 y ss.

28 WhitTaker (2008a) p. 373.

29 Barros (2006) p. 1044 y ss. 
4. En nuestra opinión, es evidente que el litigio de responsabilidad civil que sigue a una condena por conducta anticompetitiva girará en torno al daño y la relación de causalidad, sin que pueda controvertirse la existencia de ese ilícito. Entendemos, también, que el legislador quiere incentivar la interposición de acciones de responsabilidad civil como forma de cumplir y respetar las normas antimonopolio, aliciente que podría resultar seriamente disminuido hasta desaparecer si los demandantes además tuviesen que probar el dolo o la culpa de los infractores.

Sin embargo, lo antes señalado no implica que la responsabilidad civil por conductas anticompetitivas corresponda a una responsabilidad por culpa probada o presunta (culpa infraccional) como la que se aplica en materia de accidentes de tránsito, ni a una responsabilidad estricta. Por un lado, el imputar en este ámbito una responsabilidad por culpa es ignorar que el daño que ha sido infligido accidental o culpablemente es un efecto consustancial a la competencia legítima y también es desconocer que no existe un deber de cuidado entre adversarios. La competencia es una actividad peculiar porque los oponentes, inexorablemente, se dañan unos a otros sin tener obligación alguna de abstenerse de continuar haciéndolo, incluso en forma imprudente. El límite son los hechos abusivos que se hallan subsumidos en los ilícitos anticompetitivos, conductas necesariamente intencionales. Por otro lado, una responsabilidad estricta calificada por el resultado violenta el principio de culpabilidad que da sustento a la responsabilidad penal e infraccional. Asimismo, la responsabilidad estricta solo puede ser establecida por ley y el artículo 30 del DL 211 no impone tal régimen. Como señala Barros, no existe una prohibición universal de no perjudicar al prójimo. La responsabilidad estricta es excepcional y, sin duda, no tiene aplicación entre quienes compiten ofreciendo productos de diversa calidad y precio $^{30}$.

5. El dolo no es ajeno ni irrelevante en la responsabilidad por daños entre adversarios. Lo que ocurre es que el dolo está envuelto en la misma conducta anticompetitiva. A su vez, el dolo civil -intención de dañar una víctima concreta- puede ser inferido de la circunstancia que el acto anticompetitivo - previamente constatado por sentencia firmecausó un daño directo e inmediato a un competidor concreto. El dolo se puede dar por establecido a partir de la relación de causalidad entre el hecho anticompetitivo y el daño padecido por el rival que reclama una indemnización. Una vez que el actor logra probar que un hecho contrario a la libre competencia le ocasionó un perjuicio, dicho acto podrá considerarse como equivalente al delito civil y desencadenar la indemnización respectiva. Pues bien, desde el momento que en el litigio civil se acredita que la demandante fue perjudicada como consecuencia de la conducta anticompetitiva perpetrada por la demandada, es lógico y razonable colegir que esta quiso ocasionar a aquella un daño específico y diverso de aquel infligido al mercado o a un conjunto de consumidores.

En consecuencia, la responsabilidad civil entre contendores exige del dolo porque los ilícitos anticompetitivos son necesariamente intencionales. El DL 211 define la conducta anticompetitiva como aquella cuyo objeto o efecto es impedir, restringir o entorpecer la libre competencia. Si el propósito o consecuencia del acto es atentar contra la libre concu-

30 Barros (2008) pp. 314, 321 y ss. 
rrencia, aquel es forzosamente deliberado. Así se aprecia en los actos desleales orientados a alcanzar, mantener o incrementar una posición de dominio en el mercado, especialmente las prácticas predatorias o ventas bajo costo, cuyo fin es eliminar actuales competidores $\mathrm{u}$ obstruir el ingreso de futuros rivales ${ }^{31}$.

6. La interpretación que proponemos no está exenta de dificultades. En primer lugar, la intención de dañar generalmente debe ser probada ${ }^{32}$ y el artículo 30 del DL 211 no contiene una excepción a esta regla. En seguida, la conducta anticompetitiva afecta a personas indeterminadas, mientras que los delitos civiles comprenden la intención de dañar víctimas con nombre y apellido. Sin embargo, estos problemas no son insuperables.

Por un lado, por su propia naturaleza, el dolo solo puede ser acreditado indirectamente, a partir de la conducta del demandado, echando mano a las presunciones judicia$\operatorname{les}^{33}$. De hecho, la principal evidencia de la que un juez civil puede inferir la intención de dañar -o, en su caso, la culpa grave- es la misma conducta anticompetitiva antes constatada por el TDLC y/o la Corte Suprema.

Por otro lado, no es infrecuente que un ilícito anticompetitivo esté dirigido contra adversarios determinados, como es ilustrado por las conductas predatorias. Es este tipo de hechos el que ha suscitado la mayoría de los juicios de responsabilidad civil en el extranjero y en nuestro país, posiblemente porque en estos casos resulta menos complejo acreditar el nexo causal entre la infracción y el daño demandado que tratándose de conductas colusorias.

Aunque nuestro argumento probablemente no tenga incidencia en el resultado final de los juicios civiles -toda vez que en estos no se requiere probar el dolo o la culpa del demandado- ${ }^{34}$, consideramos relevante insistir, desde una perspectiva sistémica, que esta novel área de la responsabilidad aquiliana debe quedar confinada a las conductas dolosas o, en el mejor de los casos, gravemente negligentes. En suma, si se quiere mantener un equilibrio entre la libertad de competencia y la responsabilidad civil, el estándar de imputación de esta última tiene que ser el dolo o la culpa lata que corresponde a la desconsideración e imprudencia temeraria extrema hacia los intereses ajenos.

Así parecen admitirlo nuestros tribunales civiles en las escasas oportunidades en que se han pronunciado hasta ahora ${ }^{35}$. Si bien suele calificarse genéricamente como culposa la infracción a la libre competencia, el análisis más aquilatado de los hechos revela que se trata de una conducta intencional. Por ejemplo, una reciente sentencia de primer grado señaló que "la acción culposa en que incurrió [la demandada] se ha determinado en un proceso previo ante el Tribunal de Defensa de la Libre Competencia", para luego precisar que el daño moral reclamado por la actora "puede presumirse como consecuencia de las perniciosas conductas desplegadas deliberadamente por la demandada, según estableció en su sentencia el Tribunal de Defensa de la Libre Competencia, toda vez que en dicha resolución se

\footnotetext{
31 Esta definición de práctica predatoria véase en Consulta de AGIP sobre conducta de Supermercados Lider (2005).

32 Arts. 1459 y 707 CC.

33 Arts. 47 y 1712 CC; Arts. 426 y 427 CPC.

34 Barros (2006) p. 1044 y ss.

35 Véase infra III.
} 
tuvieron por demostrados ilícitos cuya finalidad era excluir ilegítimamente a la actora del mercado" 36 .

7. El examen de la causalidad y el daño excede el objeto de este artículo. Sin embargo, no podemos dejar de referirnos brevemente a este complicado tópico. Para tener éxito en sede civil, el demandante deberá demostrar que la conducta anticompetitiva perpetrada por el demandado le produjo - directa y necesariamente- un daño emergente o un lucro cesante, tal como la disminución o pérdida de cuotas de mercado, clientela, ventas o posibles negocios. Pues bien, uno de los problemas más enredados es la concurrencia de varias causas posibles de este daño -que suele ser puramente patrimonial ${ }^{37}$ - desde la moda hasta la ineficiencia del competidor afectado. Esta dificultad es todavía más acuciante si se demanda la responsabilidad civil con independencia de una declaración previa de conducta anticompetitiva ${ }^{38}$.

Este incordio también se presenta en el mismo proceso anticompetitivo. Si bien el TDLC puede evaluar las pruebas con arreglo a la sana crítica $^{39}$, la labor consistente en acreditar la infracción al DL 211 y su impacto nocivo en el mercado suele ser enmarañada. Así, por ejemplo, una colusión constatada por el TDLC fue descartada por la Corte Suprema por considerar que este ilícito no había sido acreditado inequívocamente, ya que existían explicaciones alternativas del comportamiento paralelo de los denunciados ${ }^{40}$. Estas vicisitudes ciertamente pueden contaminar los litigios de responsabilidad civil.

Como sostiene Araya, para poder indemnizar el daño alegado en sede civil es imprescindible desagregarlo del efecto negativo general del ilícito anticompetitivo, como es el costo social neto que los consumidores reales o potenciales del producto o servicio monopolizado se ven forzados a pagar en exceso. La dificultad estriba en precisar la utilidad que el actor habría percibido si el demandado no hubiese cometido la infracción ${ }^{41}$. Esta es la típica pregunta hipotética que suscita el lucro cesante y que la jurisprudencia chilena tradicionalmente rehúsa responder, denegando la indemnización de esta clase de perjuicio en las más diversas áreas de la responsabilidad civil e intentando hacer justicia por la vía de conceder, dentro de sus facultades discrecionales, una reparación del daño moral.

\section{JURISPRUDENCIA CHILENA NACIENTE}

1. En los estados miembros de la Unión Europea la litigación civil derivada de infracciones a la libre competencia ha sido exigua, lo que obedece a diversos factores. Así, por ejemplo, para explicar el estado de la cuestión en España, se apunta a la complicada prueba del daño anticompetitivo, a los elevados costos generados por estos pleitos y a la falta de

\footnotetext{
36 Rivas con Sociedad Educacional American British School (2012), cons. $17^{\circ}$ y $19^{\circ}$, respectivamente (énfasis agregado). En contra de este fallo se halla pendiente recurso de apelación, rol 2.957-2013.

37 Barros (2006) pp. 260, 284; Banfi (2012a) passim.

38 Peña (2000) p. 223 y ss.; De la Vega (2001) pp. 65, 277 y ss.; Van Dam (2006) p. 36.

39 Art. 22 DL 211. La sana crítica ha sido considerada como un criterio de valoración de la prueba adecuada para un tribunal experto como el TDLC: Philip Morris con Chiletabacos (2005).

40 V.gr., De Air Liquide Chile S.A. y Otros (2007); Fiscalía Nacional Económica con Isapre ING S.A. y Otros (2008).

41 Araya (2005) passim.
} 
incentivos para accionar, entre los cuales destaca la ausencia de daños punitivos ${ }^{42}$. Conforme al artículo 13(2) de la antigua Ley de Defensa de la Competencia española del año 1989 solo podía demandarse la responsabilidad civil contractual o extracontractual si se contaba con una sentencia firme de la Autoridad Nacional de la Competencia que declaraba la existencia de un ilícito anticompetitivo. En opinión de algunos juristas esta norma evitaba fallos contradictorios entre dicha autoridad y los tribunales civiles ${ }^{43}$. En cambio, para otros académicos dicho precepto obstaculizaba la eficacia directa de los artículos 81 y 82 del Tratado CE en los tribunales nacionales, a pesar de que estos ostentan amplia jurisdicción para conocer, entre otras, de las acciones de responsabilidad civil y nulidad. En fin, a juicio de otros autores el referido artículo 13(2) suspendía la prescripción de la acción indemnizatoria mientras estuviese pendiente la investigación del presunto acto anticompetitivo y si se constataba su existencia por sentencia ejecutoriada esta era prueba irrefragable del hecho en el proceso civil posterior $^{44}$. Por el contrario, la actual Ley de Defensa de la Competencia española 15/2007 no contempla una disposición similar al mencionado artículo 13(2). Por ende, la víctima de una conducta anticompetitiva puede accionar directa e independientemente ante los tribunales comerciales (deduciendo lo que en el sistema angloamericano se denominan stand alone actions) los que sin embargo están facultados para suspender el procedimiento hasta que la Comisión Nacional de Competencia se pronuncie sobre la infracción. Alternativamente, las víctimas pueden esperar que se declare por sentencia firme el atentado a la libre competencia y luego demandar la responsabilidad civil (follow on actions $)^{45}$.

2. En nuestro país son igualmente escasos los juicios en este sector. Asimismo, los competidores generalmente no han interpuesto acciones de responsabilidad civil con independencia de una sentencia del TDLC y/o la Corte Suprema estableciendo la infracción al DL 211. Por un lado, esta posibilidad no está reconocida en el texto del artículo 30 de dicho cuerpo legal. Por otro, la sentencia ejecutoriada del TDLC y/o la Corte Suprema produce cosa juzgada material en el litigio indemnizatorio subsiguiente en lo referente al hecho y a su calificación jurídica, de modo que el debate queda confinado al daño y al vínculo causal. Así lo confirman la doctrina nacional ${ }^{46}$ y la jurisprudencia incipiente que revisaremos a continuación. Por eso, sin una declaración de conducta anticompetitiva el demandante tendría que acreditar el ilícito ex nihilo, cuestión que además excede la jurisdicción de un tribunal civil. De hecho, el único juicio de responsabilidad civil iniciado con antelación a la entrada en vigor del artículo 30 del DL 211 se basó en un fallo de la Comisión Resolutiva que había condenado a los denunciados por infringir la libre competencia. Además, con la excepción de uno solo de los pocos pleitos iniciados bajo la vigencia del artículo 30, todos los demás se han fundado en una sentencia del TDLC y/o la Corte Suprema afirmando la existencia de la infracción. Más improbable es que se demande la res-

\footnotetext{
42 De la Vega (2001) passim.

43 Martínez (2005) passim.

44 Creus (1999) y Peña (2000) passim; De la Vega (2001) p. 348 y ss.; Ferrándiz (2002) p. 34 y ss.; ESTUPIÑÁN (2004) p. 71 y ss.

45 Una síntesis del panorama español en la materia véase en CALlol (2012) pp. 380-394.

46 Barros (2006) p. 963; VAldés (2006) pp. 281 y 309.
} 
ponsabilidad civil si dichos órganos jurisdiccionales han absuelto al denunciado, ya que la sentencia dictada por ellos constituirá una evidencia prácticamente irrefutable de la inexistencia del ilícito generador de responsabilidad patrimonial ${ }^{47}$. De hecho, en el único caso que conocemos en que se demandó la indemnización de perjuicios en base a los artículos 2314 y siguientes del Código Civil -pese a que el TDLC había desestimado una infracción al DL $211-$ la acción fue rechazada ${ }^{48}$.

Sin embargo, tal vez un competidor perjudicado podría tener mejor suerte si basa su demanda de responsabilidad en un ilícito innominado diverso de la infracción a la libre competencia. Veamos un ejemplo. Tras un proceso en que el TDLC y la Corte Suprema concluyeron que la empresa denunciada no había cometido práctica desleal ni intentado denigrar la actividad de la denunciante, sino que erróneamente y de buena fe había informado a terceros que el producto manufacturado por esta (rosa mosqueta) se encontraba contaminado ${ }^{49}$, la denunciante interpuso en contra de la denunciada una acción de responsabilidad por cuasidelito civil, obteniendo finalmente que se le indemnizara el lucro cesante ${ }^{50}$. Aunque las partes del juicio no eran rivales, la actora logró desvincular la inexistencia de una conducta anticompetitiva de la circunstancia que el demandado había actuado en forma imprudente, ocasionándole un daño puramente patrimonial. Ahora bien, si los litigantes hubiesen sido competidores quizá la demanda indemnizatoria habría sido desestimada, atendido el pronunciamiento previo del TDLC que negó toda conducta anticompetitiva. En efecto, no solo sería problemático compensar el daño económico infligido culpablemente por un contendor si se comparte la tesis de que no existe un deber de cuidado entre rivales, sino que aún más tortuoso resultaría imputar responsabilidad por un hecho que la autoridad competente ha legitimado expresamente.

3. Posiblemente el primer litigio nacional en la materia, tramitado con antelación al actual artículo 30 del DL 211, involucró a Aerovías DAP y sus socios personas naturales (la familia Pivcevic) -como demandantes- y a Lan Chile, Ladeco y National Airlines como demandadas ${ }^{51}$. La Comisión Resolutiva había declarado que las demandadas abusaron de su posición dominante en la ruta Santiago-Punta Arenas-Santiago mediante dumping, esto es, venta de grandes volúmenes a bajo precio ${ }^{52}$. Aerovías DAP ingresó a ese mercado en el mes de enero de 1996, cobrando tarifas inferiores a las históricas. La reacción de las demandadas no se hizo esperar, poniendo término inmediato al contrato de asistencia en tierra que tenían con Aerovías DAP y rebajando en forma drástica y reiterada los precios de los pasajes aéreos de dicha ruta entre los meses de marzo y mayo del mismo año. Como se sabe, este tipo de comportamiento predatorio beneficia a los consumidores en el corto plazo, ya que pueden obtener precios inferiores a los que cobra la competencia, pero en el largo pla-

\footnotetext{
47 WitKer (2000) pp. 72-73.

48 Sound Colour con United International Pictures Chile (2009).

49 Coesam S.A. con Comisión Preventiva Central (2005).

50 Sociedad Agrícola Río Sur Ltda. y Otro con Amin Merino y Otro (2011).

51 Pivcevic y otros con Lan Chile (2006).

52 Denuncia Aerovías DAP S.A. (1996).
} 
zo resultan perjudicados: una vez que el competidor derrotado es expulsado del mercado, la firma dominante consolida su posición y alza las tarifas. En palabras de la Comisión Resolutiva, las demandadas "actuaron de hecho, con el objetivo de restringir la competencia y dar señales inequívocas... de que están dispuestas a desarrollar acciones enérgicas para evitar una competencia más fuerte" ${ }^{\prime 3}$.

Aerovías DAP y sus socios demandaron la responsabilidad civil de las empresas sancionadas por ese injusto monopólico. El tribunal de primer grado estimó que las demandadas habían cometido un acto no solo anticompetitivo sino desleal, encaminado a restringir la participación de Aerovías DAP en el mercado, lo que "equivale a la intención positiva de inferir daño o sea el dolo" y afecta "la distribución esperada de beneficios, que corresponde al daño que se intenta inferir" ${ }^{4}$. Las demandadas fueron condenadas solidariamente conforme al artículo 2317 inc. $2^{\circ}$ del Código Civil. A partir de su participación conjunta y dominante en el aludido mercado, el juez presumió que las demandadas se habían concertado y perpetrado un dolo común ${ }^{55}$. La relación de causalidad entre el ilícito anticompetitivo y el daño patrimonial fue establecida con base en un informe pericial que concluyó que las demandadas habían impedido a Aerovías DAP vender los pasajes aéreos a los precios que esta había proyectado antes de ingresar al mercado relevante, acción que redujo la competitividad "a un alineamiento abusador y solidario de las tres empresas" 56 . Sin embargo, no se acreditó que el retiro de Aerovías DAP del mercado hubiese sido causado por el dumping porque esta, al evaluar su ingreso al mismo, consideró irrelevantes las prácticas predatorias que las demandadas venían ejecutando y que habían causado la salida de otros competidores. En consecuencia, el tribunal limitó la indemnización del daño emergente y del lucro cesante al período comprendido entre los meses de marzo y mayo de 1996, mientras que prescindió del lapso siguiente hasta el 31 de marzo de 1997, fecha esta última en que Aerovías DAP abandonó el mercado.

La Corte de Apelaciones y la Corte Suprema confirmaron el fallo de primer grado, pero desestimaron el daño moral por no haber sido probada la lesión al prestigio de Aerovías DAP. El daño emergente fue identificado con los costos operacionales necesarios para el funcionamiento y mantención de la aeronave de la actora (los gastos de combustible y sueldos de la tripulación) que esta fue incapaz de cubrir con la recaudación proveniente de la venta de pasajes, pues se vio obligada a rebajarlos ante la presión ejercida por las demandadas. A su vez, el lucro cesante fue asociado a las utilidades que Aerovías DAP no pudo percibir. En fin, la responsabilidad solidaria fue justificada en la colusión, término que no encontrándose definido en la ley y en atención a lo dispuesto en el artículo 20 del Código Civil, fue entendido por la Corte Suprema en su sentido natural y obvio, como "pacto ilícito en daño de tercero" según lo señala el Diccionario de la Lengua Española.

Entre los diversos aspectos de interés que reviste este juicio, en esta oportunidad destacaremos los tres siguientes: (i) es crucial contar con una declaración previa de ilícito

53 Denuncia Aerovías DAP S.A. (1996), cons. $9^{\circ}$.

54 Pivcevic y otros con Lan Chile (2006), cons. $25^{\circ}$.

55 Pivcevic y otros con Lan Chile (2006), cons. $26^{\circ}$.

56 Pivcevic y otros con Lan Chile (2006), cons. $27^{\circ}$. 
anticompetitivo, pues ella produce cosa juzgada en el juicio civil posterior respecto de la conducta y su calificación jurídica, lo que permite confinar la discusión a la existencia, especie y monto del perjuicio y a la relación causal. En cambio, el interponer una acción de responsabilidad civil autónoma es una estrategia arriesgada; (ii) en el juicio en comento se imputó responsabilidad por un delito civil, pero el dolo -la intención de eliminar al competidor- fue presumido iuris et de iure de la fijación de precios predatorios. Esto confirma el hecho de que la responsabilidad civil entre adversarios requiere del abuso del derecho a dañar, derecho que es inherente a la libertad de competir, y esto a su vez exige dolo o culpa grave. Con todo, pareciera ser que el dolo puede ser deducido con mayor facilidad de una práctica predatoria o, en general, de un abuso de posición dominante, a diferencia de otros ilícitos, especialmente los cárteles, en los que es altamente complejo identificar a sus autores y al rival perjudicado; y (iii) en todo caso, la responsabilidad civil emanó tanto del abuso de posición dominante como de la conspiración o colusión de las demandadas destinada a expulsar al contrincante. Fue este fraude común el factor que determinó la imputación de responsabilidad solidaria, que nuestra jurisprudencia ha aplicado en situaciones similares referidas a actuaciones concertadas ejecutadas con la intención de dañar a terceros, por ejemplo, cuando dos o más personas celebran una compraventa de inmueble simulada con el propósito de privar a un tercero del bien que este había adquirido en pública subasta ${ }^{57}$.

4. Bajo la vigencia del artículo 30 del DL 211 destacaremos en primer lugar el juicio entre Sound Color S.A. y United International Pictures Chile Ltda ${ }^{58}$. La exhibidora de películas Sound Color accionó de responsabilidad aquiliana en contra del distribuidor UIP, alegando que este se había negado dolosamente a alquilarle cintas de estreno simultáneo para los cines que la actora administraba en Osorno y Temuco, y que además se había coludido con Andes Films, competidor de la actora. Sound Color solicitó que le fuesen indemnizados el daño emergente (debido a la disminución en las ventas de entradas y confitería), el lucro cesante (vinculado a la pérdida de las utilidades proyectadas) y el daño moral (un supuesto desprestigio ante el público causado por la indisponibilidad de películas de exhibición simultánea).

UIP negó toda responsabilidad y colusión con otros distribuidores o exhibidores. Argumentó que el negocio de distribución cinematográfica es riesgoso -no pudiendo asegurarse si una película tendrá éxito- y competitivo, pues el éxito de la distribución depende de que el público sea persuadido y esto obedece a una multiplicidad de factores que incluyen el marketing, la calidad del filme, el lugar, oportunidad y tiempo de exhibición, etc. Asimismo, UIP sostuvo que el distribuidor puede elegir a quién y por cuánto tiempo arrienda las películas, conforme a criterios generales, razonables y objetivos que comprenden, entre otros, la ubicación geográfica del cine, la disponibilidad de última tecnología en la exhibición cinematográfica, el número de salas, la capacidad, comodidades y seguridad del cine. Estos criterios permiten predecir qué cines atraerán más público y generarán mayor recaudación. Por su parte, el exhibidor tiene el derecho a destinar sus salas de cine a las

\footnotetext{
57 Arce Cerda con Reyes y Goyenechea (2000); Barros (2006) pp. 421-422.

58 Sound Colour con United International Pictures Chile (2009).
} 
películas que desee. Por último, el único perjuicio que Sound Color pudo sufrir provino de la inyección de competencia a un mercado que ella mantenía cautivo. En este sentido, no cabe indemnizar a la actora una ganancia que ella nunca obtuvo compitiendo libremente por las preferencias de los consumidores.

El libelo fue rechazado, esencialmente, porque no se acreditó el actuar doloso ni los ilícitos anticompetitivos achacados a la demandada. Adicionalmente, se declaró que aunque los juzgados civiles pueden pronunciarse sobre la responsabilidad civil derivada de conductas anticompetitivas, solo podrían acoger la demanda si dichos ilícitos han sido declarados previamente por sentencia firme del TDLC y/o de la Corte Suprema.

En efecto, el sentenciador de primera instancia afirmó que "este Tribunal no tiene competencia para conocer acerca de los procedimientos establecidos en el mencionado D.L. 211, pero, sin perjuicio de ello, sí respecto de las indemnizaciones derivadas de la comisión y sanción de tales infracciones" y que "para que prosperara la acción deducida por la demandante, debió haberse establecido por el H. Tribunal de Defensa de la Libre Competencia, que la demandada había incurrido en los ilícitos denunciados, cosa que en la especie no ha ocurrido, por lo que no es posible acceder a las pretensiones de la actora" ${ }^{\prime 5}$. En la especie, el TDLC había absuelto a UIP60.

Como se aprecia, sin una declaración de infracción al DL 211 es virtualmente imposible imputar responsabilidad civil pues el actor mal podrá acreditar dicha conducta en el proceso civil y el tribunal debiera declararse incompetente a ese respecto. Además, la sentencia absolutoria del TDLC es un indicio de licitud de la conducta.

5. Cabe ahora referirse a dos litigios que tuvieron un demandado común -James Hardie Fibrocementos Ltda-, uno de ellos iniciado por Cementa S.A. ${ }^{61}$ y el otro por Producción Química y Electrónica Quimel S.A.62. Ambos casos figuran entre las primeras demandas indemnizatorias interpuestas conforme al art. 30 DL 211. En efecto, la Corte Suprema, acogiendo un recurso de reclamación deducido en contra de la sentencia del TDLC, declaró que en el período comprendido entre los años 2001 y 2004 James Hardie había vendido planchas de fibrocemento a precios bajo los costos de producción, alcanzando una posición dominante y expulsando a las dos firmas demandantes ${ }^{63}$. La Corte Suprema declaró que el denunciado había perseguido "eliminar a la competencia y así ganar poder en el mercado, logrando la salida de parte de ella [Quimel y Cementa] y la disminución de la participación en el mercado de Pizarreño-Pudahuel, con la intención de obtener rentas sobre normales en el largo plazo, luego de llevar a cabo una conducta de tipo secuencial, destinada a depredar primero a las presas más débiles y posteriormente al resto de la industria, para lo cual poseía los mecanismos necesarios para financiar las pérdidas económicas

59 Sound Colour con United International Pictures Chile (2009), cons. $19^{\circ}$ y $20^{\circ}$, respectivamente.

60 UIP Chile Ltda. y Andes Films S.A. contra Dictamen No 1.277 Comisión Preventiva Central (2005).

${ }_{61}$ Cementa S.A. con James Hardie Fibrocementos Ltda (2009).

62 Producción Química y Electrónica Quimel S.A. con James Hardie Fibrocementos Ltda (2009).

63 Quimica y Electrónica Quimel con James Hardie Fibrocemento Ltda. (2006). 
asociadas a la realización de dicha conducta" ${ }^{34}$. El tribunal civil, ateniéndose a los hechos y calificación jurídica establecidos por la Corte Suprema, presumió la culpa de dicha conducta predatoria, centrándose en el daño y el nexo causal.

La acción interpuesta por Quimel fue desestimada por falta de causalidad. Para ello, el tribunal tuvo en cuenta que la demandante había vendido planchas de fibrocemento a menor precio que James Hardie en el período antes referido ${ }^{65}$, que su proceso de fabricación del producto era más lento que el del demandado y que los productos de ambos tenían diversos destinatarios y mercados.

En cambio, Cementa logró acreditar que había sido una empresa solvente antes que el demandado ingresara al mercado de planchas de fibrocemento; que este le ofreció 5.8 millones de dólares norteamericanos por adquirir el 80\% de su negocio; y que, como consecuencia de sus prácticas predatorias, la demandada aumentó su cuota en el mercado mientras que las ventas de Cementa cayeron tanto que debió liquidar sus activos, presentar un convenio judicial preventivo y abandonar el mercado. La demandada sobrevivió a los efectos de su ilícito endeudándose con bancos y sociedades relacionadas y exportando sus productos a precios normales. La sentencia de primer grado también aludió al dolo del demandado, puesto que definió la práctica predatoria como "la venta de mercaderías o servicios por debajo del precio de costo, con el propósito de causar daños o perjuicios o sacar del mercado relevante a un competidor, o a prevenir que un potencial competidor entre a dicho mercado, cuando de tal acto no puede esperarse razonablemente la obtención o incremento de las ganancias, sino la expectativa de que el competidor actual o potencial abandonará la competencia o saldrá del mercado, dejando al agente con un poder sustancial o con una posición monopólica sobre el mercado relevante" ${ }^{66}$. En definitiva, la demandada fue condenada a indemnizar los tres rubros solicitados por Cementa, a saber: el daño emergente, que fue avaluado en el precio que James Hardie había ofrecido por comprar la firma demandante; el lucro cesante, que se hizo consistir en las utilidades que Cementa proyectó obtener cuando ostentaba una sólida posición financiera, rebajadas prudencialmente; y el daño moral, que fue identificado con el descrédito comercial experimentado por la actora ante sus acreedores, competidores y clientes.

Ambos casos muestran que la existencia del ilícito anticompetitivo es necesaria pero insuficiente para obtener una condena indemnizatoria: todo dependerá de que se pruebe el daño y la relación causal. Sin embargo, encontrándose pendientes sendos recursos de apelación, estos pleitos fueron transigidos en términos confidenciales, como es por lo demás la tendencia comparada.

6. Por último, nos referiremos al importante pleito entre Philip Morris (PM) y Compañía Chilena de Tabacos $(\mathrm{CCHT})^{67}$. CCHT fue sancionada por imponer barreras

\footnotetext{
64 Quimica y Electrónica Quimel con James Hardie Fibrocemento Ltda. (2006), cons. 6.

${ }^{65}$ Producción Química y Electrónica Quimel S.A. con James Hardie Fibrocementos Ltda (2009), cons. 26º.

${ }_{66}$ Cementa S.A. con James Hardie Fibrocementos Ltda (2009), cons. 25 (énfasis agregado).

${ }^{67}$ Philip Morris Chile Comercializadora Limitada con Compañia Chilena de Tabacos S.A. (2011).
} 
artificiales que impidieron a PM ingresar al mercado chileno de venta de cigarrillos ${ }^{68}$. PM demandó a CCHT la indemnización del daño emergente (sin indicar su fuente), del daño moral (a su imagen comercial) y del lucro cesante (correspondiente a los ingresos que dejó de percibir entre los años 2002 y 2005 -al no obtener el 25\% del mercado nacional-y aquellos que no podrá recibir entre los años 2006 y 2018).

En primera instancia se rechazó la demanda. No obstante que el ilícito anticompetitivo era innegable, no se probó el daño ni el nexo causal. Específicamente en lo referente al lucro cesante, PM no acreditó haber hecho los esfuerzos necesarios para alcanzar el 25\% del mercado en un breve plazo (al que recién ingresó en el año 2001) ni haber invertido suficientemente en publicidad y posicionamiento de sus productos, a diferencia de las cuantiosas y continuas inversiones efectuadas por CCHT. Además, la pretensión por adquirir el $25 \%$ del mercado chileno no se condice con la exigua tasa de crecimiento de PM (3\% anual) y el reducido mercado abarcado por esta (solo las regiones Metropolitana, V y VIII), apreciándose -a juicio del sentenciador de primer grado- "un afán de enriquecimiento con el menor o ningún esfuerzo" ${ }^{69}$.

El tribunal de alzada capitalino acogió parcialmente la apelación interpuesta por PM. Sostuvo que la actora no pudo ingresar al mercado relevante a consecuencia de las barreras impuestas por CCHT, conducta anticompetitiva que configura un ilícito civil que daña en forma cuantificable a una víctima concreta; que PM sufrió un lucro cesante entre los años 2002 y 2005 al verse privada de la posibilidad de obtener el 25\% del mercado; que PM sufrió una pérdida operacional entre los años 2001 y 2005 derivada de las inversiones efectuadas para introducir y mantener sus productos en Chile, objetivo frustrado por CCHT; que, sin embargo, conforme al curso normal de los acontecimientos, PM nunca habría ostentado más del 3\% del mercado, porque aun sin cometer ilícito alguno CCHT igualmente tendría una participación del 97\% del mercado, con presencia en todo el país. Por eso, la corte restringió la pretensión de lucro cesante al periodo 2002-2005 (US\$1.800.000) y, en cambio, atendido que la demandante no demostró poseer un $25 \%$ del mercado, consideró como meramente especulativas las utilidades proyectadas para el periodo 2006-2018. La sentencia de segunda instancia desestimó además la alegación de daño moral y daño emergente. Sin embargo, el voto disidente reconoció el lucro cesante también por el periodo 2006-2018, señalándose que los efectos patrimoniales del hecho ilícito pueden proyectarse hacia el futuro y que el lucro cesante, por definición, es futuro.

Finalmente, por sentencia de 25 de julio de 2013, la Corte Suprema dirimió este enrevesado y prolongado litigio, rechazando tanto los recursos de casación en la forma y en el fondo deducidos por CCHT como el recurso de casación en el fondo interpuesto por PM. De esta manera, la Corte Suprema por primera vez se pronuncia sobre la acción reconocida en el art. 30 del DL 211. Sin embargo, para desestimar estos recursos, la corte observó razones eminentemente procesales sin adentrarse en el análisis del lucro cesante y la relación causal efectuado por los jueces de la instancia. Habrá entonces que esperar por una nueva ocasión en que la Corte Suprema pueda interpretar estos aspectos fundamentales que, hasta

68 Philip Morris con Chiletabacos (2005).

69 Philip Morris Chile Comercializadora Limitada con Compañia Chilena de Tabacos S.A. (2011), cons. 29o. 
ahora, han mantenido tan confinada la responsabilidad civil por ilícitos anticoncurrenciales entre rivales en Chile.

\section{CONCLUSIONES}

1. La razón para no exigir el dolo como condición para imponer responsabilidad civil por ilícitos antimonopólicos entre competidores en Chile estriba en que esta clase de responsabilidad complementa al derecho de la competencia. La responsabilidad civil sigue a la declaración de conducta anticompetitiva contenida en una sentencia firme del TDLC y/o de la Corte Suprema. Por eso, quien demanda la responsabilidad civil solamente tiene que demostrar (lo que, nadie duda, es una tarea compleja) el daño particular que ha sufrido a consecuencia de dicho ilícito, perjuicio que difiere del daño inferido al mercado y a los consumidores.

Sin embargo, esto no significa que la responsabilidad extracontractual por conductas antimonopólicas tenga por base a la negligencia ni que esta sea presumida a partir de la infracción del DL 211. Ello tampoco implica que estemos ante una responsabilidad estricta u objetiva calificada por el resultado. Lo que sucede es que el dolo se infiere del hecho de que el acto anticompetitivo perjudicó directamente a un competidor en concreto.

Asimismo, parece del todo improbable que los adversarios personalmente afectados por una conducta contraria a la libre competencia hagan valer la responsabilidad civil basándose únicamente en las reglas generales del Código Civil, sin contar con una sentencia ejecutoriada que haya constatado el atentado a la libre competencia. Si tal fuera el caso, el actor se vería forzado a demostrar que el hecho del demandado configuró un ilícito anticompetitivo, además de tener que probar el dolo, el daño y la relación causal. De hecho, nuestra jurisprudencia ya ha establecido que si bien el tribunal civil es competente para pronunciarse sobre la responsabilidad civil derivada de los ilícitos anticompetitivos, solo podrá acogerse la acción si previamente quedó constatada la existencia de dichas conductas en una sentencia firme del TDLC y/o de la Corte Suprema. Por eso, resulta aún menos factible demandar la responsabilidad civil del denunciado a quien el TDLC y/o la Corte Suprema han absuelto expresamente de toda responsabilidad infraccional.

2. Aunque el juicio civil que sigue a la declaración de conducta anticompetitiva por el TDLC y/o la Corte Suprema se basa en esa constatación y las únicas materias a debatir se refieren al daño y la causalidad, no es exacto pretender aplicar en la especie una presunción de culpa o negligencia. Al igual que los actos de competencia desleal, los comportamientos anticompetitivos son deliberados, solo que ellos afectan principalmente a los consumidores y -en ciertas ocasiones- a rivales determinados. El dolo está ínsito en la infracción constitutiva del ilícito anticompetitivo. Por eso, la sentencia ejecutoriada que establece la existencia de la infracción al DL 211 es cosa juzgada respecto del hecho ilícito y su componente doloso, o gravemente descuidado, sin requerirse su prueba en sede civil.

3. Nuestros tribunales debieran interiorizarse y manejar métodos para determinar con mayor precisión la existencia, probabilidad y cuantía del daño puramente patrimonial 
derivado de los ilícitos anticompetitivos. Para ello deberán confrontar la situación real (en que se cometió un ilícito anticompetitivo) con una de carácter hipotético (que habría sucedido en ausencia de tal infracción). Sin embargo, no parece conveniente descartar la responsabilidad civil cuando no ha sido posible cuantificar el daño con exactitud si la existencia de este es indudable, pues ello solo beneficiaría al infractor. Asimismo, los jueces debieran utilizar con flexibilidad los métodos sugeridos por la doctrina, alternativa o conjuntamente. Así, ellos podrían cotejar el mercado en que se cometió el ilícito con otro mercado análogo sin ese ilícito ${ }^{70}$; comparar en el mismo mercado el periodo en que se ejecutó el ilícito con uno anterior o posterior ${ }^{71}$; determinar la cuota de mercado que el competidor habría logrado a falta de ilícito ${ }^{72}$; traer a valor presente los ingresos futuros del rival eliminado $^{73}$, entre otros procedimientos ${ }^{74}$.

4. También es necesario implementar criterios para resolver el complejo problema de las concausas. No es razonable atribuir el fracaso experimentado por un agente comercial a los actos anticompetitivos de sus contendores sin antes descartar otras explicaciones, tales como las políticas, la calidad del producto, las inversiones en marketing y distribución, los costos de producción y las ineficiencias del propio demandante. Es la falta de causalidad lo que mantiene acotada esta clase de responsabilidad civil en el Common Law, donde debe probarse que el daño emanó directamente del ilícito anticompetitivo, es decir, el actor debe pertenecer a la clase de personas o al sector económico perjudicado por el ilícito ${ }^{75}$. Sin embargo, para evitar que el infractor se aproveche de su propio dolo, la jurisprudencia no exige determinar con exactitud la cuantía del daño sino que basta una estimación justa y razonable que compare el daño real con la ganancia que el demandante habría obtenido en la ausencia de la conducta ilícita ${ }^{76}$. De hecho, el Competition Appeal Tribunal inglés, equivalente al TDLC, pero con competencia extendida a las acciones indemnizatorias, rechazó la primera demanda de responsabilidad civil por actos anticompetitivos interpuesta ante ese órgano pues aunque se había establecido el abuso de posición dominante del demandado, el actor no acreditó que el daño emanó de aquel según el criterio de la condictio sine qua non o but for test ${ }^{77}$.

\footnotetext{
70 V.gr., Bigelow et al. v. RKO Radio Pictures, Inc. (1946). Este método fue considerado aunque no aplicado dada la peculiaridad del mercado chileno de cigarrillos- en Philip Morris Chile Comercializadora Limitada con Compañia Chilena de Tabacos S.A. (2011), sentencia de primera instancia, cons. $30^{\circ}$.

${ }^{71}$ V.gr. Eastman Kodak Co. v. Southern Photo Materials Co. (1927). Este procedimiento fue aplicado en Pivcevic y otros con Lan Chile (2006).

72 V.gr., National Farmers Organization, Inc. v. Associated Milk Producers, Inc. (1988).

73 V.gr., Albrecht v. Herald Co. (1971).

74 Véase en general en LeWIN (2011) pp. 43-62.

75 Brunswick Corp. v. Pueblo Bowl-O-Mat, Inc. (1977).

76 V.gr.: Bigelow et al. v. RKO Radio Pictures, Inc. (1946), pp. 264-265, Juez Stone; Zenith Radio Corporation v. Hazeltine Research, Inc. (1969), pp. 123-124, Juez White; J. Truett Payne Company, Inc. v. Chrysler Motors Corporation (1981), pp. 565-567, Juez Rehnquist.

77 Enron Coal Services Ltd (In Liquidation) v. English Welsh \& Scottish Railway Ltd (2010). Véase BanfI (2011a) pp. 83-112.
} 
5. ¿Debe el juez civil tomar en consideración, como ha sido propuesto ${ }^{78}$, el costo social generado por el ilícito anticompetitivo, que implica una menor producción y un alza de precios, afectando consecuentemente a los consumidores? ¿Debe el TDLC tener competencia para conocer de la acción civil, dada su composición por economistas y su conocimiento en la estructura del mercado?

En nuestro concepto, la respuesta a ambas preguntas es negativa. En efecto, creemos necesario mantener separada la jurisdicción especial de la civil, atendida la diferente entidad del daño anticompetitivo -que afecta el interés público de los consumidores- del daño indemnizable en sede civil, que lesiona intereses privados. Y es que la responsabilidad civil es un mecanismo complementario de la prosecución pública de las normas sobre libre competencia. Por eso, el éxito de la acción indemnizatoria depende directamente de que el ilícito anticompetitivo sea descubierto y sancionado por el TDLC y/o la Corte Suprema.

\section{BIBLIOGRAFÍA CITADA}

AraYa, Fernando (2005): "Daño anticompetitivo y daño indemnizable: un ensayo de confrontación”, Revista Chilena de Derecho Privado, No 4: pp. 9-32.

BANFI, Cristián:

- (2012a) "Reflexiones acerca del daño puramente patrimonial", en: ElorRiaga, Fabián (coord.), Estudios de Derecho Civil VII (Santiago, Editorial Thomson Reuters) pp. 685-704.

- (2012b) "Breve revisión de la responsabilidad por interferencia de contratos del competidor en Chile a la luz del common law", Revista Chilena de Derecho Privado, $\mathrm{N}^{\circ}$ 19: pp. 165-192;

- (2012c) "Por una reparación integral del daño extracontractual limitada a los hechos dolosos o gravemente negligentes", Ius et Praxis, Año 18, N 2: pp. 3-32;

- (2011a) "Defining the competition torts as intentional wrongs", Cambridge Law Journal, vol. 70: pp. 83-112.

- (2011b) "Interferencia en contrato ajeno: limitando la responsabilidad civil del competidor", en: DE LA MAZA, Ínigo (edit.), Incumplimiento contractual: nuevas perspectivas, Cuadernos de Análisis Jurídico (Santiago, Fundación Fernando Fueyo Laneri - Universidad Diego Portales) pp. 313-361;

- (2007a) "Notas sobre el factor de atribución de la responsabilidad civil derivada de conductas contrarias a la libre y leal competencia", en: Corral, Hernán y RodríGuEZ, Sara (edits.), Estudios de Derecho Civil II (Santiago, Editorial LexisNexis) pp. 431-448;

- (2007b) "Daño entre competidores: una aproximación desde el derecho inglés", Revista Chilena de Derecho Privado, No 8: pp. 9-57;

- (2003) La asimilación de la culpa grave al dolo en la responsabilidad contractual (Santiago, Editorial LexisNexis) 279 pp.

- (2000) "La asimilación de la culpa grave al dolo en la responsabilidad contractual en Chile", Revista Chilena de Derecho, vol. 27: pp. 291-330; 
BARANDIARÁn, Edgardo (2002) "Garantías constitucionales y defensa de la competencia", Revista Chilena de Derecho, vol. 29: pp. 497-506.

BARROS, Enrique:

- (2008) "La responsabilidad civil como derecho privado", Estudios Públicos, vol. 112: pp. 309-338;

- (2006) Tratado de responsabilidad extracontractual (Santiago, Editorial Jurídica de Chile) $1230 \mathrm{pp}$.

BaYlos, Hermenegildo (1978): Tratado de derecho industrial (Madrid, Editorial Civitas) $1061 \mathrm{pp}$.

Callol, Pedro (2012): "Spain”, en: Foer, Albert y Cúneo, Jonathan (edits.), The International Handbook on Private Enforcement of Competition Law (Cheltenham, Edward Elgar Publishing Limited) pp. 380-394.

Creus, Antonio (1999): "La privatización del derecho de la competencia", Gaceta Jurídica de la Unión Europea y de la Competencia, vol. 200: pp. 55-66.

Cury, Enrique (2005): Derecho Penal Parte General (Santiago, Ediciones Universidad Católica de Chile, séptima edición) 812 pp.

De la Vega, Fernando (2001): Responsabilidad civil derivada del ilícito concurrencial. Resarcimiento del daño causado al competidor (Madrid, Editorial Civitas) $422 \mathrm{pp}$.

EstupiŃńn, Rosalía (2004): "El resarcimiento de daños y perjuicios derivado de ilícitos antitrust: problemática que plantea y posibles soluciones", Gaceta Jurídica de la Unión Europea y de la Competencia, vol. 230: pp. 63-76.

Evans, Enrique (1986): Los Derechos Constitucionales, tomo II (Santiago, Editorial Jurídica de Chile) $950 \mathrm{pp}$.

Fermandois, Arturo (2006): Derecho constitucional económico. Garantías económicas, doctrina y jurisprudencia, tomo I (Santiago, Ediciones Universidad Católica de Chile, segunda edición) $336 \mathrm{pp}$.

FERRÁnDIZ, José (2002): "Aplicación del derecho de la competencia por los órganos judiciales del orden civil", en: AAVV (eds.), Cuadernos de Derecho Judicial XI. Competencia Desleal y Defensa de la Competencia (Madrid, Editorial Consejo General del Poder Judicial) pp. 29-49.

FonT, Juan (1987): Constitución económica y derecho de la competencia (Madrid, Editorial Tecnos) $350 \mathrm{pp}$.

GuZMÁn Brito, Alejandro (2001): El derecho privado constitucional de Chile (Valparaíso, Ediciones Universitarias de la Universidad Católica de Valparaíso) 302 pp.

JaKobs, Günther (1996) Fundamentos del Derecho Penal (trad. Manuel Cancio y Enrique Peñaranda, Buenos Aires, Editorial Ad-Hoc) 240 pp.

LEWIN, Nicolás (2011): "Indemnización de perjuicios por atentados a la libre competencia: el daño anticompetitivo, su relación con el daño civil y la determinación de los perjuicios", Anales Derecho UC: pp. 43-62.

Lira, Pedro (1944): El Código Civil y el nuevo derecho (Santiago, Imprenta Nascimento) $335 \mathrm{pp}$.

Markesinis, Basil y Unberath, Hannes (2002): The German law of torts. A comparative treatise (Oxford, Hart, cuarta edición) 1050 pp. 
Martínez, Víctor (2005): "Defensa de la competencia y daños", Revista de Derecho Mercantil, vol. 255: pp. 111-142.

Nehme, Nicole y Werner, Carolina (2008): "El rol de los conceptos de orden público, buenas costumbres y buena fe en la contratación entre partes desiguales", en: GUZMÁN Brito, Alejandro (edit.) Estudios de Derecho Civil III (Santiago, Editorial LegalPublishing) pp. 647-662.

PENAA, Fernando (2000): La responsabilidad civil y la nulidad derivadas de un ilícito antitrust (Granada, Editorial Comares) 258 pp.

Peñailillo, Daniel (2006): Los bienes, la propiedad y otros derechos reales (Santiago, Editorial Jurídica de Chile) 604 pp.

Roxin, Claus (1997): Derecho penal. Parte general, tomo I (trad. Diego-Manuel Luzón et al., Madrid, Editorial Civitas, segunda edición alemana) 1071 pp.

Ruiz-Tagle, Pablo (2000): "Principios constitucionales del estado empresario", Revista de Derecho Público, vol. 62: pp. 48-65.

Tiedemann, Klaus (1993): Lecciones de derecho penal económico (Barcelona, PPU) 275 pp.

Tunc, André (1974): "Introduction", en: Tunc, André (edit.), International Encyclopedia of Comparative Law, vol. XI (Tübingen, J.C.B. Mohr) pp. 3-107.

VALDÉs, Domingo (2006): Libre competencia y monopolio (Santiago, Editorial Jurídica de Chile) $751 \mathrm{pp}$.

VAn Dam, Cees (2006): European tort law (Oxford, Oxford University Press) 538 pp.

Vergara, Enrique (2006): "El injusto monopólico (II) ¿Responsabilidad subjetiva u objetiva?", Revista de Derecho de la Empresa, vol. 5: pp. 57-68

Whittaker, Simon (2008): “The law, (c) Private law, 10. The law of obligations", en: Bell, John et al. (edits.), Principles of French law (Oxford, Oxford University Press, segunda edición) pp. 294-452.

Witker, Jorge (2000): Derecho de la competencia en América. Canadá, Chile, Estados Unidos y México (Santiago, Fondo de Cultura Económica) 344 pp.

\section{NORMAS CITADAS}

Constitución Política de la República de Chile.

DFL $\mathrm{N}^{\circ} 1$, que fijó el texto refundido, coordinado y sistematizado del DL $\mathrm{N}^{\circ} 211$ de 1973. Diario Oficial, 7 de marzo de 2005.

Ley No 20.169, que regula la competencia desleal. Diario Oficial, 16 de febrero de 2007.

Código Civil

Código de Procedimiento Civil

\section{JURISPRUDENCIA CITADA}

\section{ChILENA}

Arce Cerda con Reyes y Goyenechea (2000): Corte Suprema, 4 de enero de 2000 (recurso de casación en el fondo), Fallos del Mes, No 494, p. 3148. 
Cementa S.A. con James Hardie Fibrocementos Ltda (2009): 260 Juzgado Civil de Santiago, 24 de abril de 2009 (acción de indemnización de perjuicios por infracción del DL 211), rol 13.272-2007.

Coesam S.A. con Comisión Preventiva Central (2005): Corte Suprema, 16 de junio de 2005 (recurso de reclamación), rol 5.719-2004.

Consulta de AGIP sobre conducta de Supermercados Lider (2005): Corte Suprema, 26 de mayo de 2005 (recurso de reclamación), rol 4.927-2004.

De Air Liquide Chile S.A. y Otros (2007): Corte Suprema, 22 de enero de 2007 (recurso de reclamación), rol 5.057-2006.

Denuncia Aerovías DAP S.A. (1996): Comisión Resolutiva, Resolución № 479, 31 de diciembre de 1996.

Fiscal Nacional Económico con Copec y Otras (2005): Corte Suprema, 26 de octubre de 2005 (recurso de reclamación), rol 3.327-2005.

Fiscal Nacional Económico con Ultramar y Otros (2006): Corte Suprema, 28 de diciembre de 2006 (recurso de reclamación), rol 3.395-2006.

Fiscalía Nacional Económica con Isapre ING S.A. y Otros (2008): Corte Suprema, 28 de enero de 2008 (recurso de reclamación), rol 4.052-2007.

Intergas con Dirección de Vialidad de la Décima Región de los Lagos (2004): Corte Suprema, 23 de agosto de 2004 (recurso de amparo económico), rol 2.943-2004.

Philip Morris con Chiletabacos (2005): Tribunal de Defensa de la Libre Competencia, Sentencia $\mathrm{N}^{\circ}$ 26, 5 de agosto de 2005, confirmada por Corte Suprema, 10 de enero de 2006 (recurso de reclamación), rol 4.332-2005.

Philip Morris Chile Comercializadora Limitada con Compañia Chilena de Tabacos S.A. (2011): 10 Juzgado Civil de Santiago, 25 de enero de 2010 (acción de indemnización de perjuicios por infracción del DL 211), rol 19.655-2009; Corte de Apelaciones de Santiago, 8 de noviembre de 2011 (recurso de apelación), rol 1520-2010; Corte Suprema, 25 de julio de 2013, rol 1.339-2012 (recursos de casación en la forma y en el fondo).

Pivcevic y otros con Lan Chile (2006): 4o Juzgado Civil de Santiago, 22 de junio de 2000, rol 4.831-97; Corte de Apelaciones de Santiago, 14 de julio de 2004, rol 5.954-1999; y Corte Suprema, 27 de diciembre de 2006 (acción de indemnización de perjuicios por infracción del DL 211), rol 5.835-2004.

Producción Quimica y Electrónica Quimel S.A. con James Hardie Fibrocementos Ltda (2009): 26ㅜ Juzgado Civil de Santiago, 23 de junio de 2009 (acción de indemnización de perjuicios por infracción del DL 211), rol 2.191-2007.

Química y Electrónica Quimel con James Hardie Fibrocemento Ltda. (2006): Tribunal de Defensa de la Libre Competencia, Sentencia No 39, 13 de junio de 2006, revocada por Corte Suprema, 29 de noviembre de 2006 (recurso de reclamación), rol 3.449-2006.

Rivas con Sociedad Educacional American British School (2012): $27^{\circ}$ Juzgado Civil de Santiago, 19 de diciembre de 2012 (acción de indemnización de perjuicios por infracción del DL 211), rol 7.123-2011 (pendiente recurso de apelación Corte de Apelaciones de Santiago, rol 2.957-2013).

Sentencia Tribunal Constitucional, Rol No 244, 26 de agosto de 1996 (Ley No 4.601). 
Sociedad Agrícola Río Sur Ltda. y Otro con Amin Merino y Otro (2011): Corte de Apelaciones de Concepción, 30 de diciembre de 2008, rol 360-2005; Corte Suprema, 15 de noviembre de 2011 (recurso de casación en el fondo), rol 3.516-2009.

Sound Colour con United International Pictures Chile (2009): 10 Juzgado Civil de Santiago, 30 de diciembre de 2005, rol 782-2004, confirmada por Corte de Apelaciones de Santiago, 30 de junio de 2009 (acción de indemnización de perjuicios por infracción del DL 211), rol 1.361-2006.

UIP Chile Ltda. y Andes Films S.A. contra Dictamen No 1.277 Comisión Preventiva Central (2005): Tribunal de Defensa de la Libre Competencia, Sentencia No 16, 20 de mayo de 2005 (avocación en recurso de reclamación).

Voissnet S.A. con Compañia de Telecomunicaciones de Chile S.A. (2007): Corte Suprema, 4 de julio de 2007 (recurso de reclamación), rol 6.236-2006.

\section{ESTADOUNIDENSE}

Albrecht v. Herald Co. (1971): United States Court of Appeals, Eighth Circuit, 17 de noviembre de 1971 (appeal), 452 F.2d 124 (8 ${ }^{\text {th }}$ Cir. 1971).

Bigelow et al. v. RKO Radio Pictures, Inc. (1946): Supreme Court of Justice, 25 de febrero de 1946 (certiorari), 237 U.S. 251 (1946).

Brunswick Corp. v. Pueblo Bowl-O-Mat, Inc. (1977): Supreme Court of Justice, 25 de enero de 1977 (certiorari), 429 U.S. 477 (1977).

Eastman Kodak Co. v. Southern Photo Materials Co. (1927): Supreme Court of Justice, 21 de febrero de 1927 (writ of error), 237 U.S. 359 (1927).

J. Truett Payne Company, Inc. v. Chrysler Motors Corporation (1981): Supreme Court of Justice, 18 de mayo de 1981 (certiorari), 451 U.S. 557 (1981).

National Farmers Organization, Inc. v. Associated Milk Producers, Inc. (1988): United States Court of Appeals, Eighth Circuit, 5 de julio de 1988 (appeal), 850 F.2d 1286 ( $8^{\text {th }}$ Cir. 1988).

Zenith Radio Corporation v. Hazeltine Research, Inc. (1969): Supreme Court of Justice, 19 de mayo de 1969 (certiorari), 395 U.S. 100 (1969).

\section{EUROPEA}

Völk v. Vervaecke (1969): Tribunal de Justicia de la Unión Europea, 9 de julio de 1969 (cuestión prejudicial), Caso 5/69 [1969] CMLR 273.

\section{INGLESA}

Enron Coal Services Ltd (In Liquidation) v. English Welsh \& Scottish Railway Ltd (2010): Competition Appeal Tribunal, 9 de febrero de 2010 (damages claim), [2009] CAT 36; Court of Appeal, 19 de enero de 2011 (appeal), [2011] EWCA Civ 2 